\title{
A simple method to score digital dermatitis in dairy cows in the milking parlor
}

\author{
A. Relun, ${ }^{*} \dagger \ddagger \S \#{ }^{1}$ R. Guatteo, ${ }^{\star} \ddagger \S \#$ P. Roussel, ${ }^{\star} \dagger$ and N. Bareille ${ }^{\star} \ddagger \S \#$ \\ *UMT Cattle Herd Health Control, F-44307 Nantes, France \\ †Livestock Institute, Department Welfare, Health, Traceability, Hygiene, 149 rue de Bercy, F-75595 Paris, France \\ $\ddagger$ ONIRIS, Nantes Atlantic National College of Veterinary Medicine, Food Science and Engineering UMR 1300 Bio-aggression, \\ Epidemiology and Risk Analysis, F-44307 Nantes, France \\ §INRA, UMR 1300 Bio-aggression, Epidemiology and Risk Analysis, F-44307 Nantes, France \\ \#Université Nantes Angers Le Mans, F-44307 Nantes, France
}

\section{ABSTRACT}

The diagnosis of digital dermatitis (DD) in cows is crucial for researchers to evaluate the effectiveness of control measures. The objective of this study was to evaluate intra- and inter-observer agreement and accuracy of a simple method to score DD lesions that is based on the inspection of cleaned feet in the milking parlor with a swiveling mirror and a powerful headlamp. The hind feet of 242 Holstein cows from 4 farms were inspected concurrently by 5 observers (to assess inter-observer agreement) during 2 consecutive milkings (to assess intra-observer agreement). This inspection was followed by an inspection of the feet in a trimming chute, considered to be the gold standard test, to test for accuracy. The reliability of the method was assessed using both the 5 M-stages scoring system (M0 to M4, M standing for Mortellaro) and a simplified M-stages scoring system in which the M3 and M4 stages are merged. As most disagreements concerned the M3 and M4 stages, performance was improved with the simplified M-stages scoring system. With this simplified system, the method had good intraobserver agreement [percent of overall raw agreement $(\mathrm{PA})=80 \%$, weighted kappa $\left(\kappa_{\mathrm{w}}\right)=0.71$, and good inter-observer agreement $\left.\left(\mathrm{PA}=77 \%, \kappa_{\mathrm{w}}=0.66\right)\right]$. The agreement with the gold standard test was moderate $\left(\mathrm{PA}=69 \%, \kappa_{\mathrm{w}}=0.58\right)$. Considering absence versus presence of a DD lesion on a foot, the method had good sensitivity (0.90) and specificity (0.80). The time spent for inspection varied from 30 to $60 \mathrm{~s}$ per cow. Inspection of cleaned feet with a swiveling mirror and a powerful headlamp in the milking parlor is a reliable, cost- and time-friendly method, which may be useful for both farmers and researchers, especially when the DD status of many dairy cows has to be evaluated concomitantly. The reliability of this method might be improved by

Received December 1, 2010.

Accepted June 22, 2011.

${ }^{1}$ Corresponding author: anne.relun@oniris-nantes.fr using more precise descriptive criteria for the discrimination of each M-stage.

Key words: dairy cow, digital dermatitis, scoring system, reliability

\section{INTRODUCTION}

Digital dermatitis (DD) is a widespread, contagious, multifactorial disease involving environmental, management and microbial factors. This is currently one of the major causes of infectious lameness in cattle (Berry et al., 2004). First described in 1974 in Italy (Cheli and Mortellaro, 1974), the reported incidence of the disease has increased worldwide over the past few decades due to the enlargement and merger of dairy herds (Read and Walker, 1998; Holzhauer et al., 2006b; Yano et al., 2009). Digital dermatitis is becoming a serious issue for dairy farmers because the disease negatively affects animal welfare and production (Fourichon et al., 1999; Cha et al., 2010), it is difficult to eliminate, and the efficacy of control measures is largely unpredictable (Laven and Logue, 2006).

The detection of DD is a key for the control of the disease. Farmers must detect the lesions as early as possible to improve the cure rates of individual topical treatments (Hernandez and Shearer, 2000; Bathina et al., 2002). Researchers also need to measure the largescale prevalence of DD to evaluate the effectiveness of management and treatment strategies. The determination of a cow's DD status currently is based on the visual inspection of the feet to identify characteristic circumscribed skin lesions, mostly observed between the heels of the hind limbs (Read and Walker, 1998; Berry et al., 2004). As the clinical appearance of DD lesions varies over the course of the disease, more than just the assumption of absence or presence of a DD lesion is needed to determine the severity and cured status of a DD lesion (Holzhauer et al., 2008a). A 5 M-stages scoring system, based on the one first described by Döpfer et al. (1997), recently was amended by a consortium of international experts (Greenough et al., 2008), with M standing for Mortellaro, and the M-stages representing 
stages during the course of DD that range from M0 $=$ no lesion to $\mathrm{M} 4=$ chronic stage. Although precise characteristics are given to identify each stage, a degree of subjectiveness is inevitable, as the classification is based on the visual inspection of the feet. Observation conditions, the tools used, and the experience of the observers consequently can lead to different classifications of the same lesion.

Traditionally, foot inspection to detect DD is performed by lifting the foot in a trimming chute. Although this method currently is the most accurate to score DD lesions, it is labor-consuming and stressful for cows, and therefore, not well adapted to frequent assessments of the cows' DD status, especially when an entire herd has to be examined. Several inspection methods on standing animals have been tested but were not fully satisfactory because they were either too expensive (Laven, 1999), too time-consuming (Rodriguez-Lainz et al., 1998), or insufficiently accurate (Thomsen et al., 2008). Furthermore, none of these studies investigated either the accuracy of DD scoring or intra- and inter-observer agreement, although this information is important for the interpretation of the results on DD scoring within and between studies.

The objective of our study was to assess intra- and inter-observer agreement and accuracy of a method based on simple tools, comprised of a powerful headlamp and a telescopic swiveling mirror, to detect and score DD lesions in the milking parlor using the Mstages scoring system.

\section{MATERIALS AND METHODS}

\section{Study Design and Data Collection}

To assess inter-observer agreement, it was estimated that the optimal combination of subjects and observers was 427 feet (214 cows) and 5 observers (Walter et al., 1998), with an expected inter-observer agreement of 0.65 , an acceptable inter-observer agreement of 0.6 or higher, $\alpha=0.05$, and $\beta=0.20$. The hind feet of 242 lactating Holstein cows from 4 farms (all lactating cows, namely 50, 53, 69, and 70 cows on farms 1, 2, 3, and 4, respectively, the farm number determined by the chronological order of the inspection visits) were examined by 5 observers to evaluate the scoring method. Farms were selected using 2 convenience criteria: the farm had been affected by DD for over 1 yr and the farm's cows were milked in a milking parlor. The farms were recruited through hoof trimmers reporting recurrent DD lesions in those farms, without precise estimation of its prevalence. Three farms had a herringbone milking parlor and one had a parallel milking parlor (farm 4).
Inspection of the feet was performed by the corresponding author and 4 veterinarians from the bovine clinical staff of the Nantes Atlantic National College of Veterinary Medicine (France) who had varied experience in scoring DD lesions. They were trained by the corresponding author in the use of the M-stages scoring system with a total panel of 40 pictures of DD lesions used during 3 training sessions held before the start of the study.

The 5 M-stage scoring system used was those first described by Döpfer et al. (1997) and validated at the Fifteenth International Symposium on Lameness in Ruminants (Greenough et al., 2008); M0 refers to feet where no circumscribed skin lesions are present; M1 is an early stage lesion with a small, circumscribed, red to gray epithelial defect of less than $2 \mathrm{~cm}$ in diameter; M2 is the classic ulcerative (bright red) or granulomatous (red-gray) stage with a diameter $>2 \mathrm{~cm}$; M3 is the healing stage within 1 to $2 \mathrm{~d}$ after topical treatment where an acute DD lesion has covered itself with a firm, scab-like material; and M4 is the late chronic stage characterized by a dyskeratotic lesion (mostly thickened epithelium), surface proliferation, or both. For all DD scorings done during the study, each observer had a guide with 1 DD lesion picture per M-stage and the main characteristics of the M-stage to refer to it when needed.

To assess intra- and inter-observer agreement, the 5 observers simultaneously scored the hind feet of each lactating cow in the milking parlor during 2 consecutive milkings without consulting each other. Before each inspection, the hind feet were cleaned with a medium-pressure water hose when the cows had entered the milking parlor and stood in the stalls. The hind feet then were inspected and scored for DD during the milking with a powerful headlamp [Petzl Tikka Plus; Petzl, Crolles, France $(34.90 €)$ ] and a telescopic swiveling mirror [Inspection mirror 1PK390G; Prokit's Industries Co. Ltd., Hsin Tien, Taiwan (8.88 €)] as illustrated in Figure 1.

To test for overall agreement with the gold standard test, all of the cows were restrained in a trimming chute and scored for DD following the second milking. The hind feet were cleaned with a brush and water before being scored. The DD score was formulated by having all 5 observers and an experienced hoof trimmer reach a general consensus (1 trimmer on the first and second farms and 2 on the third and fourth farms).

For all of the observations, the cow's identification number (ear tag), foot involved, the M-stage, and location of the DD lesions were recorded. The anatomical location of the DD lesion was specified as illustrated in Figure 2. During milking, the time spent for the observation of each side of the milking parlor was also recorded to assess the compatibility of this method with a regular milking. Recording forms were used to 

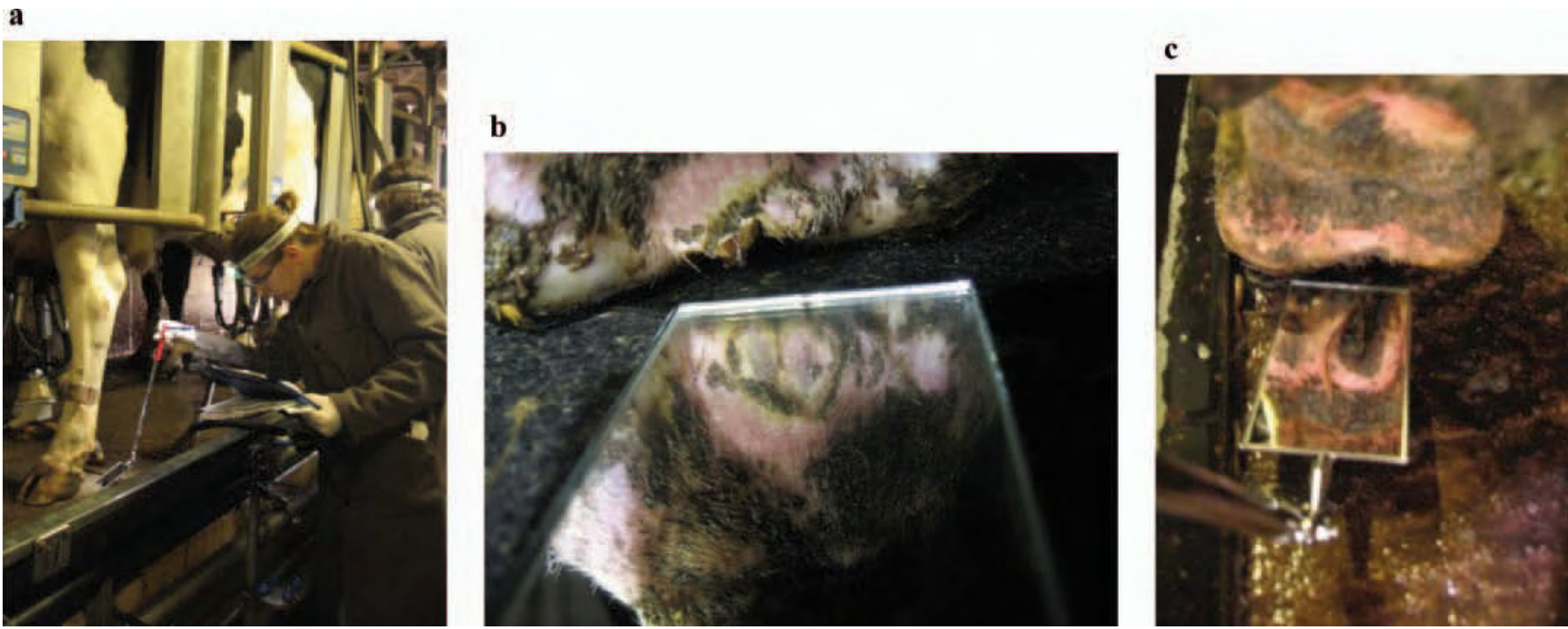

Figure 1. Inspection of the hind feet during milking with a headlamp and a swiveling mirror (a), showing M2 stage (classical ulcerative or granulomatous stage; b), and showing M4 stage (chronic stage; c) of digital dermatitis lesions. Color version available in the online PDF.

simplify recording during milking, with 1 sheet per milking parlor side, taking into account the number of places per quay.

The study took place between April and May 2009 in Brittany and Pays-de-la-Loire in Western France.

\section{Data Analysis}

All of the data were entered in Microsoft Office Excel version 11 (Microsoft Corp., Redmond, WA) and analyzed using SAS 9.1.3 (SAS Institute Inc., Cary, NC). The statistical unit was the hind foot. The statistical analyses were performed using PROC FREQ of SAS with the agree option for agreement coefficients. Statistics were estimated for all farms and by farm, and 95\% confidence intervals were calculated. Agreement statistics were calculated using the classic M-stages scoring system and a simplified M-stages scoring system in which the M3 and M4 stages were merged (M0/ M1/M2/M34). As in routine practice, the feet would be cleaned only once in the milking parlor before inspection, only data from the first milking were used to assess inter-observer agreement and agreement with the gold Standard test. a

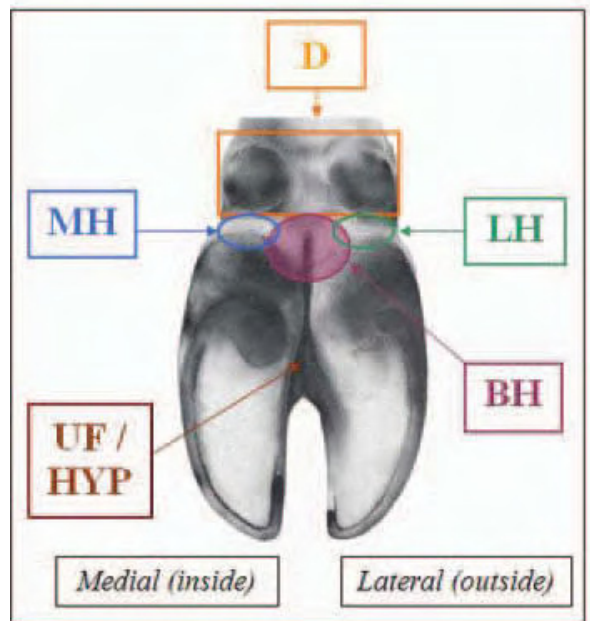

b

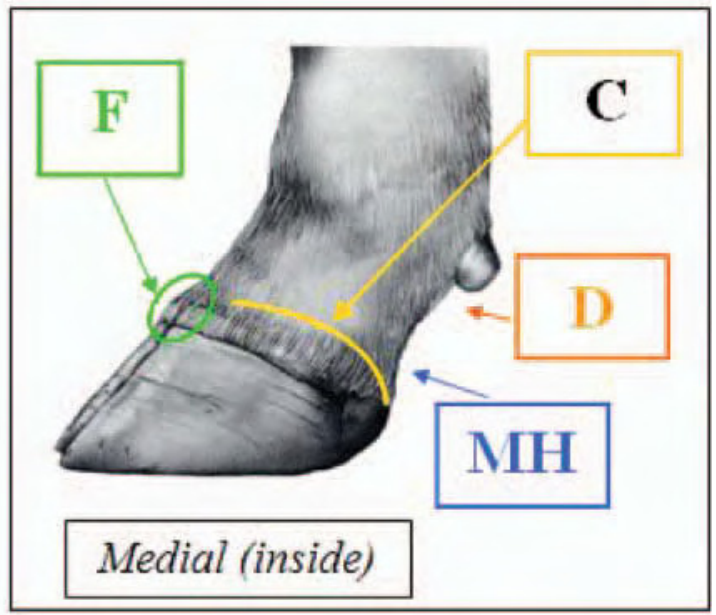

Figure 2. Anatomical areas defined for the location of digital dermatitis lesions (a: under feet view; b: medial view). $\mathrm{BH}=\mathrm{between}$ heel; $\mathrm{MH}=$ medial heel; $\mathrm{LH}=$ lateral heel; $\mathrm{D}=$ around the dewclaws; $\mathrm{C}=$ on the coronet; $\mathrm{F}=$ on the front; UF $=$ under the foot in the interdigital space; HYP = under the foot, on an interdigital hyperplasia. Color version available in the online PDF. 
Attribution of a DD Score to a Foot. In case of observing more than 1 lesion per foot, the most severe M-stage was assigned according to the hierarchy proposed as M2 $>$ M1 $>$ M4 $>$ M3. Indeed, M2 is the most infectious and painful stage of DD, and thus, is considered to be the most severe (Döpfer et al., 1997; Holzhauer et al., 2008a); M1 is the early acute stage that precedes or appears between episodes of M2 lesions (Döpfer, 2009); M3 and M4 correspond, respectively, to the healing and chronic stages of DD, and are thus less severe stages. Both can still be infectious (Mumba et al., 1999) but M4 is more likely to be followed by an M1 or an M2 lesion than M3 (Holzhauer et al., 2008a, Döpfer, 2009).

Description of the DD Lesions Observed During Trimming. The anatomical location of the different stages of the lesions was described. The proportion of each M-stage observed in the hind feet during trimming was calculated, considering the score of a foot, for all farms and by farm. The average prevalence of hind feet with DD was calculated for all farms and by farm.

Evaluation of Intra- and Inter-Observer Agreement. Intra-observer agreement was measured by comparing the scores attributed by each observer to a foot on the 2 consecutive milkings, whereas interobserver agreement was measured by comparing the scores attributed by the 5 observers during the first milking only.

Intra- and inter-observer agreement was assessed using the percent overall agreement $\left(\mathbf{P A}_{\mathbf{o}}\right)$, the agreement beyond chance $(\boldsymbol{\kappa})$, and weighted kappa coefficients $\left(\kappa_{\mathrm{w}}\right)$. In the first step, $\mathrm{PA}_{\mathrm{o}}, \kappa$, and $\kappa_{\mathrm{w}}$ statistics were calculated within each observer scorings and between each observer pairs. In the second step, the means and 95\% confidence intervals for within and between observers were calculated.

The $\mathrm{PA}_{\mathrm{o}}$ was calculated (Fleiss, 1975; Hripcsak and Heitjan, 2002) as

Percent overall agreement $=$

$\underline{\text { number of exact agreements } \times 100 \%}$.

total number of observations

The $\kappa$ value quantifies the agreement beyond chance (Cohen, 1960). When using ordered scorings, $\kappa_{w}$ may be used to take into account that the relative disagreement between scorings may not be the same for adjacent scores as for distant scores (Cohen, 1968). The $\kappa_{\mathrm{w}}$ was calculated using linear weights (Cicchetti and Allison, 1971), with the scores in the same order as described above (M2 > M1 > M4 > M3 > M0). The $\kappa$ and $\kappa_{\mathrm{w}}$ were interpreted using the guidelines recommended by Landis and Koch (1977): $\leq 0=$ poor, 0.01 to $0.20=$ slight, 0.21 to $0.40=$ fair, 0.41 to 0.60
$=$ moderate, 0.61 to $0.80=$ good, and 0.81 to $1=$ almost perfect.

The analysis of lack of agreement was conducted by calculating the percent agreement and disagreement per M-stage pairs and the percent specific agreement $\left(\mathbf{P A} \mathbf{A}_{\mathrm{s}}\right)$ per M-stage. In the first step, these statistics were calculated within each observer scorings and between each observer pairs. In the second step, the mean values for within and between observers were calculated. The $\mathrm{PA}_{\mathrm{s}}$ was calculated (Fleiss, 1975; Hripcsak and Heitjan, 2002) as

$$
\begin{gathered}
\text { Percent specific agreement }= \\
\frac{2 \times \text { number of exact agreements for each M-stage } \times 100 \%}{\text { total number of observations in this M-stage }} .
\end{gathered}
$$

Overall Agreement with the Gold Standard Test. Overall agreement with the gold standard test was evaluated by comparing the scores attributed during the first milking and during trimming. The agreement was assessed using $\mathrm{PA}_{o}, \kappa$, and $\kappa_{\mathrm{w}}$ coefficients. These statistics first were estimated for each observer and then the means and $95 \%$ confidence intervals were calculated.

The analysis of lack of agreement was conducted by calculating the percent agreement and disagreement per M-stage pairs and $\mathrm{PA}_{\mathrm{s}}$ per M-stage. In the first step, these statistics were calculated within each observer scorings and between each observer pairs. In the second step, the mean values for within and between observers were calculated. The percent agreement and disagreement per M-stage pairs were calculated by comparing the scores given during milking to those given during trimming, with the scores attributed during trimming considered to be the true scores. The $\mathrm{PA}_{\mathrm{s}}$ was calculated as described previously.

Sensitivity (Se) and specificity $(\mathbf{S p})$ also were calculated, with the scores attributed in the trimming chute considered to be the gold standard and those attributed during the first milking as a diagnostic test. For the analyses, a score of M0 indicated absence of DD and scores of M1, M2, M3, and M4 as presence of DD. The Se and $\mathrm{Sp}$ were first estimated for each observer and then mean values were calculated. Positive (PPV) and negative (NPV) predictive values also were calculated to illustrate the performance of the detection method in the milking parlor under field conditions.

\section{RESULTS}

\section{Description of the DD Lesions Observed on the Hind Feet}

The anatomical location of the different M-stages found on the hind feet during trimming are displayed in 
Table 1. Of the 484 feet inspected during trimming, 217 (45\%) were diagnosed with at least 1 DD lesion. Most DD lesions (90\%) were found on the back of the foot between the heels. Most of the feet $(\mathrm{n}=195 ; 90 \%)$ had only 1 lesion. Among them, 8 feet had a DD lesion under the foot ( 1 foot with an M4 lesion in the interdigital space, 2 feet with an M1 lesion, 4 feet with an M2 lesion, and 1 foot with an M4 lesion on an interdigital hyperplasia). On average, 43 feet $(9 \%)$ were scored M1, $56(12 \%) \mathrm{M} 2,42(9 \%) \mathrm{M} 3$, and $76(16 \%)$ M4. These proportions varied between farms, as illustrated in Figure 3. Thus, considering absence (M0) versus presence of DD (M1 to M4), the average prevalence of hind feet with DD in the trimming chute was 0.45 . It was 0.77 , $0.20,0.35$, and 0.52 , respectively, in farms 1 to 4 .

\section{Performance of the DD Scoring in the Milking Parlor}

Intra- and Inter-Observer Agreement. Results on intra-observer agreement for all farms and by farm using the 5 and the 4 M-stages scoring systems are displayed in Table 2. Intra-observer agreement was good with both the 5 and the $4 \mathrm{M}$-stages scoring systems (average $\mathrm{PA}_{\mathrm{o}}=74 \%, \kappa=0.62, \kappa_{\mathrm{W}}=0.70$, and $\mathrm{PA}_{\mathrm{o}}=$ $80 \%, \kappa=0.66, \kappa_{\mathrm{W}}=0.71$, respectively). The results on inter-observer agreement are displayed in Table 3. Using the $5 \mathrm{M}$-stages scoring system, inter-observer agreement was moderate to good, depending on the farm, with, on average, $\mathrm{PA}_{\mathrm{o}}=66 \%, \kappa=0.51$, and $\kappa_{\mathrm{W}}=$ 0.63 . It was improved when using the $4 \mathrm{M}$-stages scoring system (average $\mathrm{PA}_{o}=77 \% ; \kappa=0.61 ; \kappa_{\mathrm{W}}=0.66$ ). For both intra- and inter-observer agreement, the best results were observed on the 2 last farms inspected.

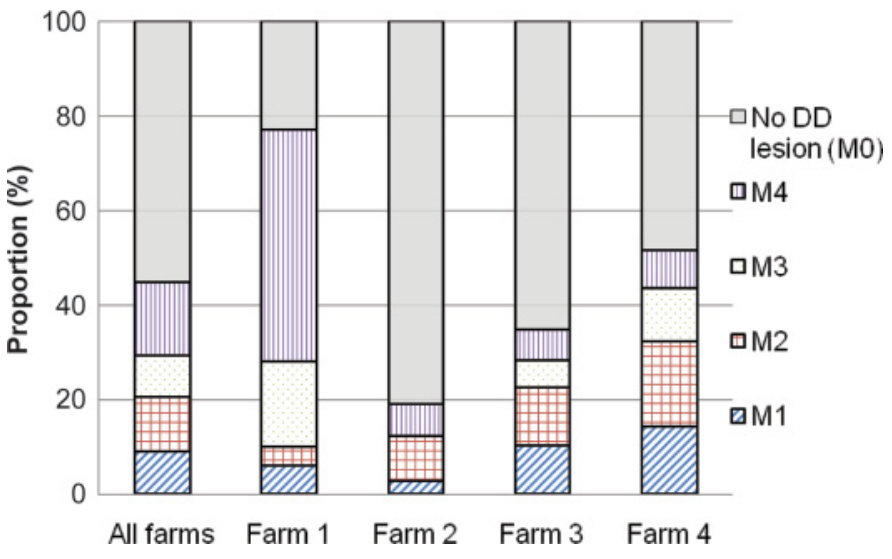

Figure 3. Proportion of the different stages of digital dermatitis (DD) lesions (M0 to M4) observed for all farms and per farm during trimming. $\mathrm{M} 0=$ no circumscribed skin lesions are present; $\mathrm{M} 1=$ an early stage lesion with a small, circumscribed, red to gray epithelial defect of less than $2 \mathrm{~cm}$ in diameter; $\mathrm{M} 2=$ the classic ulcerative (bright red) or granulomatous (red-gray) stage with a diameter $>2 \mathrm{~cm}$; M3 $=$ the healing stage within 1 to $2 \mathrm{~d}$ after topical treatment where an acute DD lesion has covered itself with a firm, scab-like material; M4 $=$ the late chronic stage characterized by a dyskeratotic lesion (mostly thickened epithelium), surface proliferation, or both. Color version available in the online PDF.

The percent of agreement/disagreement per M-stage pairs for both intra- and inter-observer agreement are presented on Table 4. Most of the disagreements concerned stages M3 and M4 (average 5\% and 10\% of all observations within and between observers, respectively) followed by disagreements over stages M0 and M3 (average $6 \%$ and $7 \%$ within and between observers, respectively) and over stages M0 and M4 (average $6 \%$ within and between observers). For all observers, specific agreement within and between observers was

Table 1. Distribution (no.; \% in parentheses) of the anatomical location of the different M-stages of digital dermatitis (DD) attributed to the 484 hind feet during trimming

\begin{tabular}{|c|c|c|c|c|c|c|c|}
\hline \multirow[b]{2}{*}{${\text { DD } \text { stage }^{1}}^{1}$} & \multirow[b]{2}{*}{ No. } & \multicolumn{6}{|c|}{ Location $^{2}$} \\
\hline & & $\mathrm{BH}$ & $\mathrm{F}$ & LH & $\mathrm{MH}$ & UND & HYPU \\
\hline DD lesion & 217 & $195(90)$ & $2(1)$ & $8(4)$ & $1(0)$ & $2(1)$ & $9(4)$ \\
\hline M1 & 43 & $34(79)$ & $0(0)$ & $3(7)^{3}$ & $1(2)^{3}$ & $1(2)^{4}$ & $4(9)^{5}$ \\
\hline M2 & 56 & $47(84)$ & $2(4)^{3}$ & $3(5)^{3}$ & $0(0)$ & $0(0)$ & $4(7)^{3}$ \\
\hline M3 & 42 & $42(100)$ & $0(0)$ & $0(0)$ & $0(0)$ & $0(0)$ & $0(0)$ \\
\hline M4 & 76 & $72(95)$ & $0(0)$ & $2(3)^{3}$ & $0(0)$ & $1(1)^{3}$ & $1(1)^{3}$ \\
\hline
\end{tabular}

${ }^{1} \mathrm{M} 1$ = an early stage lesion with a small, circumscribed, red to gray epithelial defect of less than $2 \mathrm{~cm}$ in diameter; M2 = the classic ulcerative (bright red) or granulomatous (red-gray) stage with a diameter $>2 \mathrm{~cm}$; M3 $=$ the healing stage within 1 to $2 \mathrm{~d}$ after topical treatment where an acute DD lesion has covered itself with a firm, scab-like material; M4 = the late chronic stage characterized by a dyskeratotic lesion (mostly thickened epithelium), surface proliferation, or both.

${ }^{2} \mathrm{BH}=$ between heels; $\mathrm{F}=$ in front of the foot; $\mathrm{LH}=$ on the lateral heel; $\mathrm{MH}=$ on the medial heel; $\mathrm{UND}=$ under the foot; HYPU = under the foot on an interdigital hyperplasia.

${ }^{3} \mathrm{No}$ DD lesion on other locations.

${ }^{4} \mathrm{M} 3$ lesion between the heel.

${ }^{5}$ One foot with an M3 lesion between heels, one foot with an M4 lesion between heels, and two feet with no DD lesion on other locations. 
Table 2. Average level of agreement within observers for the scoring of digital dermatitis (DD) in the milking parlor using the 5 M-stages (M0 to M4) or the simplified 4 M-stages (M0/M1/M2/M34) scoring systems for all farms and by farm ${ }^{1}$

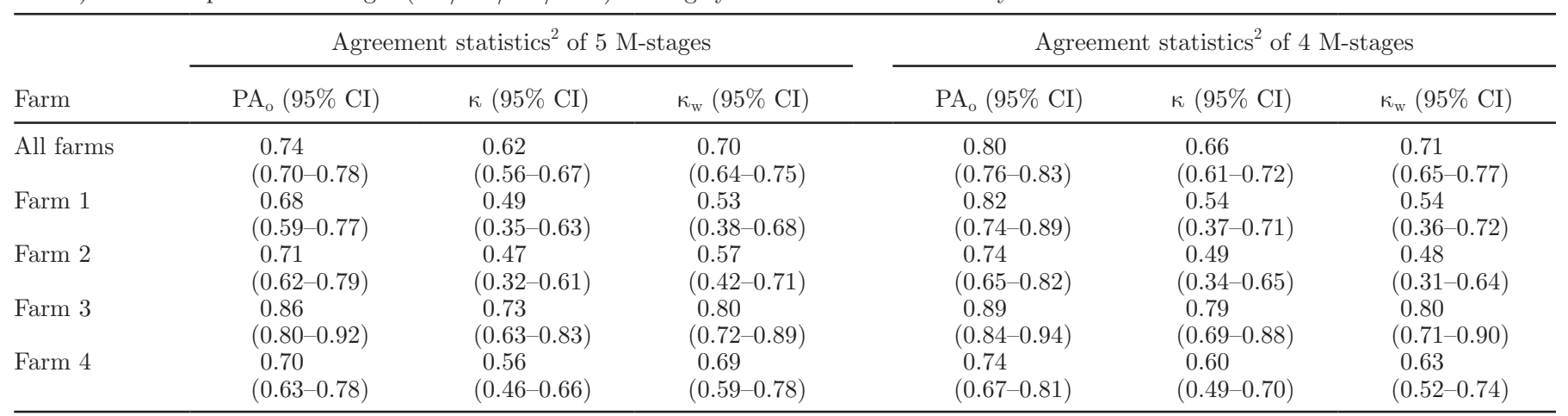

${ }^{1} \mathrm{M} 0=$ no circumscribed skin lesions are present; $\mathrm{M} 1$ = an early stage lesion with a small, circumscribed, red to gray epithelial defect of less than $2 \mathrm{~cm}$ in diameter; M2 = the classic ulcerative (bright red) or granulomatous (red-gray) stage with a diameter $>2 \mathrm{~cm}$; M3 = the healing stage within 1 to $2 \mathrm{~d}$ after topical treatment where an acute DD lesion has covered itself with a firm, scab-like material; M4 = the late chronic stage characterized by a dyskeratotic lesion (mostly thickened epithelium), surface proliferation, or both.

${ }^{2}$ Mean overall percent agreement $\left(\mathrm{PA}_{\mathrm{o}}\right)$, the agreement beyond chance $(\kappa)$, and weighted kappa $\left(\kappa_{\mathrm{w}}\right)$.

good for M0, M2 and M34 (average $\mathrm{PA}_{\mathrm{s}}=86 \%, 72 \%$ and $77 \%$ within observers respectively, and $\mathrm{PA}_{\mathrm{s}}=85 \%$, $58 \%$ and $74 \%$ between observers respectively). It was moderate for M4 (average $\mathrm{PA}_{\mathrm{s}}=69 \%$ and $55 \%$ within and between observers respectively), and was fair for $\mathrm{M} 1$ (average $\mathrm{PA}_{\mathrm{s}}=41 \%$ and $33 \%$ within and between observers respectively) and $\mathrm{M} 3$ (average $\mathrm{PA}_{\mathrm{s}}=49 \%$ and $36 \%$ within and between observers respectively).

Overall Agreement with the Gold Standard Test. Results for the overall agreement between scorings in the milking parlor and in the trimming chute are presented in Table 5. On average, agreement between milking and trimming was moderate with the 5 M-stages classification (average $\mathrm{PA}_{\mathrm{o}}=62 \%, \kappa=0.44$, and $\kappa_{\mathrm{W}}=0.58$ ). Results were improved with the $4 \mathrm{M}$ stages scoring system (average $\mathrm{PA}_{\mathrm{o}}=69 \%, \kappa=0.51$, and $\left.\kappa_{\mathrm{W}}=0.58\right)$, except for farm 2 . The best results were observed on the 2 last farms. These results did not significantly differ when considering only DD lesions that were located on the feet (not under the feet; data not shown). Results of Se, Sp, PPV, and NPV for the detection of a DD lesion [absence (M0) versus presence (M1 to M4)] are displayed, on average and by farm, in Table 6. Using scoring in the trimming chute as the gold standard, the milking parlor method had, on average, a sensitivity of 0.90 (95\% CI: $0.86-0.94$ ) and a specificity of 0.80 (95\% CI: $0.75-0.85)$. Thus, with a true prevalence of $45 \%$ of feet with a DD lesion, $79 \%$ of the feet detected with a DD lesion during milking actually had a DD lesion (PPV) and 91\% detected free of DD during milking also were observed free of DD during trimming (NPV). The worst results were

Table 3. Average level of agreement between observers for the scoring of digital dermatitis (DD) in the milking parlor using the 5 M-stages (M0 to M4) or the simplified 4 M-stages (M0/M1/M2/M34) scoring systems for all farms and by farm ${ }^{1}$

\begin{tabular}{|c|c|c|c|c|c|c|}
\hline \multirow[b]{2}{*}{ Farm } & \multicolumn{3}{|c|}{ Agreement statistics ${ }^{2}$ of $5 \mathrm{M}$-stages } & \multicolumn{3}{|c|}{ Agreement statistics ${ }^{2}$ of $4 \mathrm{M}$-stages } \\
\hline & $\mathrm{PA}_{\mathrm{o}}(95 \% \mathrm{CI})$ & $\kappa(95 \% \mathrm{CI})$ & $\kappa_{\mathrm{w}}(95 \% \mathrm{CI})$ & $\mathrm{PA}_{\mathrm{o}}(95 \% \mathrm{CI})$ & $\kappa(95 \% \mathrm{CI})$ & $\kappa_{\mathrm{w}}(95 \% \mathrm{CI})$ \\
\hline Farm 1 & $\begin{array}{l}0.52 \\
(0.42-0.61)\end{array}$ & $\begin{array}{l}0.31 \\
(0.18-0.43)\end{array}$ & $\begin{array}{l}0.41 \\
(0.27-0.55)\end{array}$ & $\begin{array}{l}0.74 \\
(0.65-0.82)\end{array}$ & $\begin{array}{l}0.47 \\
(0.31-0.62)\end{array}$ & $\begin{array}{l}0.49 \\
(0.33-0.66)\end{array}$ \\
\hline Farm 2 & $\begin{array}{l}0.63 \\
(0.54-0.72)\end{array}$ & $\begin{array}{l}0.38 \\
(0.25-0.50)\end{array}$ & $\begin{array}{l}0.50 \\
(0.36-0.64)\end{array}$ & $\begin{array}{l}0.71 \\
(0.63-0.80)\end{array}$ & $\begin{array}{l}0.46 \\
(0.32-0.61)\end{array}$ & $\begin{array}{l}0.48 \\
(0.32-0.63)\end{array}$ \\
\hline Farm 4 & $\begin{array}{l}0.67 \\
(0.59-0.75)\end{array}$ & $\begin{array}{l}0.52 \\
(0.42-0.62)\end{array}$ & $\begin{array}{l}0.66 \\
(0.56-0.75)\end{array}$ & $\begin{array}{l}0.75 \\
(0.68-0.82)\end{array}$ & $\begin{array}{l}0.62 \\
(0.52-0.72)\end{array}$ & $\begin{array}{l}0.68 \\
(0.57-0.78)\end{array}$ \\
\hline
\end{tabular}

${ }^{1} \mathrm{M} 0=$ no circumscribed skin lesions are present; $\mathrm{M} 1=$ an early stage lesion with a small, circumscribed, red to gray epithelial defect of less than $2 \mathrm{~cm}$ in diameter; M2 = the classic ulcerative (bright red) or granulomatous (red-gray) stage with a diameter $>2 \mathrm{~cm}$; M3 = the healing stage within 1 to $2 \mathrm{~d}$ after topical treatment where an acute DD lesion has covered itself with a firm, scab-like material; M4 = the late chronic stage characterized by a dyskeratotic lesion (mostly thickened epithelium), surface proliferation, or both.

${ }^{2}$ Mean overall percent agreement $\left(\mathrm{PA}_{\mathrm{o}}\right)$, the agreement beyond chance $(\kappa)$, and weighted kappa $\left(\kappa_{\mathrm{w}}\right)$. 
Table 4. Level of agreement (in bold)/disagreement by M-stage pairs (given in \%) for the scoring of digital dermatitis (DD) in the milking parlor within and between observers

\begin{tabular}{|c|c|c|c|c|c|c|c|c|c|c|}
\hline \multirow[b]{2}{*}{ DD stage ${ }^{1}$} & \multicolumn{5}{|c|}{ Within observers } & \multicolumn{5}{|c|}{ Between observers } \\
\hline & M0 & M1 & M2 & M3 & M4 & M0 & M1 & M2 & M3 & M4 \\
\hline M0 & 42 & 1 & 1 & 6 & 6 & 42 & 1 & 1 & 7 & 6 \\
\hline M1 & & 2 & 1 & 1 & 2 & & 1 & 2 & 1 & 2 \\
\hline M2 & & & 6 & 1 & 2 & & & 5 & 1 & 3 \\
\hline M3 & & & & 7 & 5 & & & & 6 & 10 \\
\hline M4 & & & & & 17 & & & & & 14 \\
\hline
\end{tabular}

observed on farm 2. The results were similar for each observer (data not shown).

The percent agreement and disagreement per Mstage pair for scores given during milking in relation to those attributed during trimming are presented in Table 7. Most of the disagreements were over scores M3 and M4. Among the feet scored M2 during trimming, $42 \%$ were scored similarly during milking, but $29 \%$ were scored M4. Only 14\% of feet scored M1 during trimming were scored the same value during milking, others being scored either M4 (37\%), M3 (20\%), or M2 $(19 \%)$. Results on specific agreements are displayed in Figure 4. Specific agreement was good for M0 (average $\mathrm{PA}_{\mathrm{s}}=85 \%$ ), fair for $\mathrm{M} 1$ and $\mathrm{M} 3$ (average $\mathrm{PA}_{\mathrm{s}}=20$ and $28 \%$, respectively), and moderate for M2 and M4 (average $\mathrm{PA}_{\mathrm{s}}=50$ and $44 \%$, respectively). It was good for M34 (average $\mathrm{PA}_{\mathrm{s}}=61 \%$ ).

Time Needed for DD Scoring in the Milking Parlor. The mean time spent on observations in the milking parlor decreased during the study from 60 to
$31 \mathrm{~s}$ per cow [60 (SD: $4 \mathrm{~s}$ ), 50 (SD: $4 \mathrm{~s}), 37$ (SD: $1 \mathrm{~s}$ ), and $31 \mathrm{~s}$ (SD: $1 \mathrm{~s}$ ) for farms 1, 2, 3, and 4, respectively].

\section{DISCUSSION}

The aim of this study was to evaluate intra- and inter-observer agreement and the accuracy of a simple method, using a new tool and a validated DD scoring system: a method that could be used in the milking parlor to detect and score DD lesions in dairy cows. As DD scoring is based on the visual inspection of feet, the results of any DD scoring method relies on the accuracy of the definitions of the scoring system, the accuracy of the tool used for the inspection, the observation conditions, and the experience and the accuracy of the observers.

The Se and Sp of the method presented in this paper reflected quite a good accuracy for the detection of a DD lesion at the prevalence observed. Sensitivity was higher on almost all farms than that found in

Table 5. Average level of agreement between digital dermatitis (DD) scores attributed during milking and trimming (gold standard test) using the 5 M-stages (M0 to M4) or the simplified 4 M-stages (M0/M1/M2/M34) scoring systems for all farms and by farm ${ }^{1}$

\begin{tabular}{|c|c|c|c|c|c|c|}
\hline \multirow[b]{2}{*}{ Farm } & \multicolumn{3}{|c|}{ Agreement coefficients $^{2}$ of $5 \mathrm{M}$-stages } & \multicolumn{3}{|c|}{ Agreement coefficients $^{2}$ of 4 M-stages } \\
\hline & $\mathrm{PA}_{\circ}(95 \% \mathrm{CI})$ & $\kappa(95 \% \mathrm{CI})$ & $\kappa_{\mathrm{w}}(95 \% \mathrm{CI})$ & $\mathrm{PA}_{\mathrm{o}}(95 \% \mathrm{CI})$ & $\kappa(95 \% \mathrm{CI})$ & $\kappa_{\mathrm{w}}(95 \% \mathrm{CI})$ \\
\hline Farm 1 & $\begin{array}{l}0.55 \\
(0.46-0.65)\end{array}$ & $\begin{array}{l}0.34 \\
(0.21-0.48)\end{array}$ & $\begin{array}{l}0.45 \\
(0.31-0.59)\end{array}$ & $\begin{array}{l}0.75 \\
(0.67-0.83)\end{array}$ & $\begin{array}{l}0.48 \\
(0.32-0.64)\end{array}$ & $\begin{array}{l}0.52 \\
(0.35-0.69)\end{array}$ \\
\hline Farm 2 & $\begin{array}{l}0.63 \\
(0.54-0.72)\end{array}$ & $\begin{array}{l}0.27 \\
(0.13-0.40)\end{array}$ & $\begin{array}{l}0.34 \\
(0.28-0.59)\end{array}$ & $\begin{array}{l}0.63 \\
(0.54-0.72)\end{array}$ & $\begin{array}{l}0.26 \\
(0.12-0.40)\end{array}$ & $\begin{array}{l}0.23 \\
(0.09-0.38)\end{array}$ \\
\hline Farm 4 & $\begin{array}{l}0.60 \\
(0.52-0.68)\end{array}$ & $\begin{array}{l}0.43 \\
(0.34-0.53)\end{array}$ & $\begin{array}{l}0.58 \\
(0.48-0.69)\end{array}$ & $\begin{array}{l}0.65 \\
(0.57-0.73)\end{array}$ & $\begin{array}{l}0.49 \\
(0.38-0.59)\end{array}$ & $\begin{array}{l}0.53 \\
(0.42-0.65)\end{array}$ \\
\hline
\end{tabular}

${ }^{1} \mathrm{M} 0=$ no circumscribed skin lesions are present; M1 = an early stage lesion with a small, circumscribed, red to gray epithelial defect of less than $2 \mathrm{~cm}$ in diameter; M2 = the classic ulcerative (bright red) or granulomatous (red-gray) stage with a diameter $>2 \mathrm{~cm}$; $33=$ the healing stage within 1 to $2 \mathrm{~d}$ after topical treatment where an acute DD lesion has covered itself with a firm, scab-like material; M4 = the late chronic stage characterized by a dyskeratotic lesion (mostly thickened epithelium), surface proliferation, or both.

${ }^{2}$ Mean overall percent of agreement $\left(\mathrm{PA}_{\mathrm{o}}\right)$, the agreement beyond chance $(\kappa)$, and weighted kappa $\left(\kappa_{\mathrm{w}}\right)$. 
Table 6. Average prevalence and sensitivity (Se), specificity (Sp), and predictive values (PPV: positive predictive value; NPV: negative predictive value) for the scoring of digital dermatitis in the milking parlor for absence (M0) versus presence (M1 to M4), considering scoring in the trimming chute as a gold standard ${ }^{1}$

\begin{tabular}{|c|c|c|c|c|c|c|}
\hline Farm & No. $^{2}$ & $\begin{array}{c}\text { Average } \\
\text { prevalence }\end{array}$ & $\begin{array}{c}\mathrm{Se} \\
(95 \% \mathrm{CI})\end{array}$ & $\underset{(95 \% \mathrm{CI})}{\mathrm{Sp}}$ & $\begin{array}{c}\text { PPV } \\
(95 \% \text { CI })\end{array}$ & $\begin{array}{c}\text { NPV } \\
(95 \% \text { CI })\end{array}$ \\
\hline All farms & 484 & 0.45 & $\begin{array}{l}0.90 \\
(0.86-0.94)\end{array}$ & $\begin{array}{l}0.80 \\
(0.75-0.85)\end{array}$ & $\begin{array}{l}0.79 \\
(0.75-0.82)\end{array}$ & $\begin{array}{l}0.91 \\
(0.88-0.93)\end{array}$ \\
\hline Farm 1 & 100 & 0.77 & $\begin{array}{l}0.94 \\
(0.88-0.99)\end{array}$ & $\begin{array}{l}0.67 \\
(0.48-0.86)\end{array}$ & $\begin{array}{l}0.91 \\
(0.85-0.96)\end{array}$ & $\begin{array}{l}0.77 \\
(0.69-0.85)\end{array}$ \\
\hline Farm 2 & 106 & 0.20 & $\begin{array}{l}0.79 \\
(0.62-0.96)\end{array}$ & $\begin{array}{l}0.68 \\
(0.59-0.78)\end{array}$ & $\begin{array}{l}0.38 \\
(0.29-0.47)\end{array}$ & $\begin{array}{l}0.93 \\
(0.88-0.98)\end{array}$ \\
\hline Farm 3 & 138 & 0.35 & $\begin{array}{l}0.91 \\
(0.83-0.99)\end{array}$ & $\begin{array}{l}0.92 \\
(0.87-0.98)\end{array}$ & $\begin{array}{l}0.86 \\
(0.80-0.92)\end{array}$ & $\begin{array}{l}0.95 \\
(0.91-0.99)\end{array}$ \\
\hline Farm 4 & 140 & 0.52 & $\begin{array}{l}0.87 \\
(0.79-0.95)\end{array}$ & $\begin{array}{l}0.81 \\
(0.72-0.90)\end{array}$ & $\begin{array}{l}0.83 \\
(0.77-0.89)\end{array}$ & $\begin{array}{l}0.85 \\
(0.79-0.91)\end{array}$ \\
\hline
\end{tabular}

${ }^{1} \mathrm{M} 0=$ no circumscribed skin lesions are present; $\mathrm{M} 1$ = an early stage lesion with a small, circumscribed, red to gray epithelial defect of less than $2 \mathrm{~cm}$ in diameter; $\mathrm{M} 2=$ the classic ulcerative (bright red) or granulomatous (red-gray) stage with a diameter $>2 \mathrm{~cm} ; \mathrm{M} 3=$ the healing stage within 1 to $2 \mathrm{~d}$ after topical treatment where an acute DD lesion has covered itself with a firm, scab-like material; M4 = the late chronic stage characterized by a dyskeratotic lesion (mostly thickened epithelium), surface proliferation, or both.

${ }^{2}$ Number of hind feet observed by farm.

previous studies on DD detection in a standing animal (Rodriguez-Lainz et al., 1998; Laven, 1999; Thomsen et al., 2008). In those studies, Se was quite good when a sophisticated tool was used $(\mathrm{Se}=0.85$ and 0.79 for right and left feet, respectively, using a modified boroscope; Laven, 1999) or if a long time was spent on the inspection of the feet $(\mathrm{Se}=0.72$ spending approximately $2 \mathrm{~min} / \mathrm{cow}$; Rodriguez-Lainz et al., 1998). However, when these conditions were not met, Se was only moderate ( $\mathrm{Se}=0.65$; Thomsen et al., 2008). Overall, Sp was similar to those found by Laven (1999; Sp $=0.83$ and 0.85 for right and left feet, respectively) and Thomsen et al. $(2008 ; \mathrm{Sp}=0.84)$, but lower than that found by Rodriguez-Lainz et al. (1998; $\mathrm{Sp}=0.99$. Therefore, we found that the overall Se and Sp of the method presented in this paper are reliable enough for the detection of a DD lesion with the prevalence observed in this study. This means that, in most cases, the definition of the M-stages and the tool used were able to efficiently diagnose the presence of a DD lesion on a foot, taking into account all possible appearances of a DD lesion. Nevertheless, we generally obtained better results in the 2 last farms visited and poor results in the second farm visited. In farm 2 , a low wall by the dairy platform rendered it difficult to clean the feet well or position the mirror correctly. In farms with such a low wall by the dairy platform, we advise either spending more time to ensure the correct cleaning and inspection of the feet, or to lift the feet in a trimming chute. Sensitivity and Sp may also have been affected by the proportion of the different M-stages in the farms. The M0 stage was not often confused with another M-stage, but when it was, it was mainly with the M3 and M4 stages. Therefore, the Sp may be lower in farms with a lot of M3 or M4 lesions, as was observed in the first farm visited. Finally, one should keep in mind that, given the quite good Se and imperfect Sp, the prevalence of DD lesions will be overestimated, particularly

Table 7. Levels of agreement (in bold)/disagreement by M-stage pairs (no.; \% in parentheses) for the scoring of digital dermatitis (DD) in the milking parlor compared with DD scoring during trimming

\begin{tabular}{|c|c|c|c|c|c|}
\hline \multirow{2}{*}{$\begin{array}{l}\text { Milking } \\
\text { DD stage }\end{array}$} & \multicolumn{5}{|c|}{ Trimming } \\
\hline & M0 & M1 & M2 & M3 & M4 \\
\hline M0 & $212(80)$ & $5(11)$ & $7(12)$ & $4(11)$ & $7(10)$ \\
\hline M1 & $2(1)$ & $6(14)$ & $7(12)$ & $1(3)$ & $4(6)$ \\
\hline M2 & $1(0)$ & 8 (19) & $23(42)$ & $2(4)$ & $4(6)$ \\
\hline M3 & $29(11)$ & $8(19)$ & $3(5)$ & $17(40)$ & $17(23)$ \\
\hline M4 & $23(9)$ & $16(37)$ & $16(29)$ & $18(43)$ & $43(56)$ \\
\hline Total & 267 & 43 & 56 & 42 & 76 \\
\hline
\end{tabular}

${ }^{1} \mathrm{M} 0=$ no circumscribed skin lesions are present; $\mathrm{M} 1$ = an early stage lesion with a small, circumscribed, red to gray epithelial defect of less than $2 \mathrm{~cm}$ in diameter; $\mathrm{M} 2=$ the classic ulcerative (bright red) or granulomatous (red-gray) stage with a diameter $>2 \mathrm{~cm}$; $\mathrm{M} 3=$ the healing stage within 1 to $2 \mathrm{~d}$ after topical treatment where an acute DD lesion has covered itself with a firm, scab-like material; M4 = the late chronic stage characterized by a dyskeratotic lesion (mostly thickened epithelium), surface proliferation, or both. 
5432

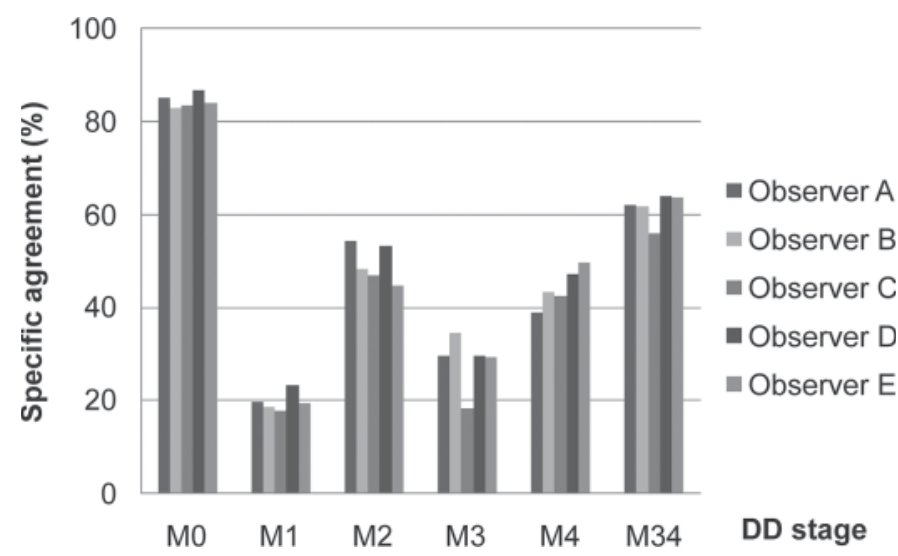

Figure 4. Percent specific agreement per stage of digital dermatitis (DD) lesions (M0 to M4) and per observer between scores attributed during the first milking and trimming. $\mathrm{M} 0=$ no circumscribed skin lesions are present; $\mathrm{M} 1$ = an early stage lesion with a small, circumscribed, red to gray epithelial defect of less than $2 \mathrm{~cm}$ in diameter; M2 $=$ the classic ulcerative (bright red) or granulomatous (red-gray) stage with a diameter $>2 \mathrm{~cm}$; M3 = the healing stage within 1 to $2 \mathrm{~d}$ after topical treatment where an acute DD lesion has covered itself with a firm, scab-like material; M4 = the late chronic stage characterized by a dyskeratotic lesion (mostly thickened epithelium), surface proliferation, or both.

on farms where prevalence is moderate to low (Martin, 1984). Moreover, because of imperfections of Se and Sp leading to the misclassification of DD lesions, the effectiveness of control measures will be underestimated in cohort studies in which our method is used (Dohoo et al., 2003).

In addition to the ability to detect a DD lesion, we wanted to assess the accuracy of the method for the scoring of a DD lesion. We found that some M-stages were less discriminated, resulting in an average moderate agreement between scores attributed in the milking parlor and in the trimming chute. The M3 stage was the least differentiated stage. It was often confused with M4, either between scorings in the milking parlor and in the trimming chute, or between observer scorings, or even within observer scorings. As M3 is just a transient stage that is followed immediately by M4 when the scab falls off, we considered that they could be merged into 1 stage: M34. The combination of the 2 stages seems relevant and will not impair the biological interpretation of the lesions in terms of infectiousness or clinical implication. After M3, M1 was the least differentiated stage. This was not very surprising, as this stage only differs from M2 by the diameter of the lesion (less than $2 \mathrm{~cm}$ for M1), which can be very small (less than 0.5 $\mathrm{cm}$ in diameter) and, in addition, can be found in a M4 stage (Döpfer, 2009). M1, thus, often was confused with M2 and M4. We think, however, that this stage should be differentiated from M2 and M4, as it does not have the same clinical and epidemiological implication: M1 lesions are less infectious (Mumba et al., 1999) and less painful (Holzhauer et al., 2008a) than M2 lesions. The confusion between M1 and M2 must be due to the tool that is insufficiently accurate to discriminate lesions by their size. The tool could be improved by adding rulers along the mirror. Concerning confusions between M1 and M4, 2 explanations can be given. First, the upright position of the cows during inspection prevented the detection of lesions located under the feet in the interdigital space and, like Holzhauer et al. (2008a), we found that some acute lesions, mostly M1, were located under the feet, mostly on interdigital hyperplasia. Thus, these feet may have been diagnosed as M4 in the milking parlor, whereas an M1 lesion was observed under the feet in the trimming chute, in addition to an M4 lesion located between the heels. Second, most of the small M1 (less than $0.5 \mathrm{~cm}$ in diameter) were surrounded by thickened epithelium, as appears in M4 lesions. They might have been observed more often in the trimming chute, particularly when they were located in the interdigital space between the heels. However, the biological and epidemiological interpretation of this type of lesion, an M1 lesion with a diameter smaller than $0.5 \mathrm{~cm}$ and surrounded by thickened epithelium, may be problematic. Indeed, this lesion might be a lesion at the end of the process of healing and, thus, may not have the same evolution nor the same epidemiological implication as an early stage also scored M1 in the scoring system defined by Greenough et al. (2008). To restrict the definition of M1 to the early stage of DD lesion, one could consider as M1 lesions only those surrounded by normal epithelium, the others being scored as M4.1 as recently proposed by Döpfer (2009). Nevertheless, a more precise definition of the M1 stage would be useful to improve its biological and epidemiological interpretation.

Previous studies of DD scoring of a standing animal focused on Se and Sp to assess the validity of the method used (Rodriguez-Lainz et al., 1998; Laven, 1999; Thomsen et al., 2008). We wanted to assess intra- and inter-observer agreement in addition to accuracy, as the method would be of little use if the people using it cannot agree on the interpretation of the DD scores. Moreover, we know that the assessment of intra- and inter-agreement is particularly important with regard to DD diagnosis, as previous studies on foot lesion scoring found a poor degree of agreement between observers for DD scoring even though the observation conditions were better than those of this study (Manske et al., 2002; Holzhauer et al., 2006a). When using photographic slides to assess inter- and intra-observer agreement, Manske et al. (2002) found a good intra-observer agreement $(\kappa \geq 0.6)$ but a moderate inter-observer agreement $(\kappa=0.46)$. When 
inspecting feet in a trimming chute, Holzhauer et al. (2006a) also found a fair inter-observer agreement ( $\kappa$ : 0.1 to 0.7 between observer pairs, mostly $\leq 0.5$ ). In our study, where observers had been trained with pictures before the start of the study, the $\kappa$ values indicated only good average intra- and inter-observer agreement. This lack of agreement mainly corresponded to confusions between M3, M4, and M0 stages. The confusions between M3 and M4 lesions or M3 and M0 lesions may be partially explained by a difference in cleanliness of feet between first and second milking. Indeed, even if the feet were cleaned with a water hose before each inspection, some dirt scab could remain, particularly during the first milking, and thus, a lesion scored as M3 during the first milking could be diagnosed as an M0 or M4 lesion during the second milking. This highlights the importance of a good cleaning of the feet before inspection. The confusion between M0 and M4 lesions may have involved some M4 lesions that are really slim. For such lesions, the distinction between M4 and M0 is not obvious. More precise criteria, like a minimal size, would be useful in improving the discrimination of these slim M4 lesions. Nevertheless, as M3 and M4 lesions are often considered as cured lesions in trials assessing the effectiveness of DD control measures (Somers et al., 2005; Holzhauer et al., 2008b), the confusions between M0, M3, and M4 will not impair the interpretation of cure rate or rate of new infections. We thus assume that results on the effectiveness of control measures will be quite comparable within and between studies in which our method is used to score DD lesions.

As the feet should be cleaned only once in the milking parlor when using our method, only the data of the first milking were used to assess inter-observer agreement and agreement of our method with the gold standard test. When using only data of the second milking, results were quite similar for inter-observer agreement and slightly improved for agreement with the gold standard test (data not shown). As indicated previously, this might be due to a better visualization of the lesions after a second washing of the feet. As the differences of the results for inter-observer agreement and agreement with the gold standard test are quite slight between the 2 milkings, results of intra-observer agreement may have been artificially only slightly decreased by the second washing.

Finally, we wanted to highlight some practical implications of the use of our method to score DD lesions. This method presents some practical advantages, as it is cheap, easy to perform and not stressful for the cows. The time needed for the observations was shorter than those spent for an inspection in a trimming chute ( 1 to 15 min; Rodriguez-Lainz et al., 1998; Thomsen et al., 2008) but was longer than those reported by Thomsen et al. (2008) and may delay routine milking procedures. Nevertheless, we observed that this time decreased during the study, probably due to the additional experience gained by the observers. We, therefore, advise to conduct some collective training sessions with inspection of the feet in the milking parlor on farms where DD is present before the use of this scoring method by different observers. This may be particularly useful when DD scoring has to be made during milking and when the observers are not accustomed to the scoring system.

\section{CONCLUSIONS}

The inspection of cleaned feet in the milking parlor with simple tools, consisting of a powerful headlamp and a swiveling mirror, is a quite reliable method for trained observers to detect and score DD lesions using a simplified M-stages scoring system. As small lesions and lesions in the interdigital space may be missed, this method will not be as accurate as the inspection of the feet in a trimming chute, but can be a good time- and cost-friendly alternative DD scoring method in research projects, especially in large herds or when frequent evaluations of DD status are needed. Dairy farmers also may find this method useful in their daily herd management to detect and rapidly treat affected feet and to follow the evolution of the prevalence of DD in their herd.

\section{ACKNOWLEDGMENTS}

We thank the farmers, the hoof trimmers, and the 4 observers (ONIRIS, Nantes, France) involved in this study. We also acknowledge Dörte Döpfer (University of Wisconsin, Madison), Jean Prodhomme (CFPPA of Rennes-Le Rheu, France), and Marc Delacroix (veterinary practitioner, Boen, France) for their contribution to the preparation of the study. Finally, we thank Thierry Brun (Livestock Institute, Paris, France) and Anne Lehebel (INRA, Nantes, France) for their help regarding the statistical analyses.

\section{REFERENCES}

Bathina, H., J. Lising, T. Hemling, J. Siciliano-Jones, and J. Calaman. 2002. Correlation of the stage of lesion to the effectiveness of treatment of digital dermatitis. Pages 381-382 in Proc. 12th Intern. Symp. Lameness Ruminants, Orlando, FL.

Berry, S. L., R. L. Walker, D. H. Read, D. W. Hird, and R. A. Ertze. 2004. The current state of knowledge on (papillomatous) digital dermatitis in dairy cattle: with particular reference to control. Pages 130-137 in Proc. 13th Intern. Symp. 5th Conf. Lameness Ruminants, Maribor, Slovenia.

Cha, E., J. A. Hertl, D. Bar, and Y. T. Grohn. 2010. The cost of different types of lameness in dairy cows calculated by dynamic programming. Prev. Vet. Med. 97:1-8. 
Cheli, R., and C. Mortellaro. 1974. Digital dermatitis in cattle (La dermatite digitale del bovino). Pages 208-213 in VIII International meeting on diseases of cattle. VI Congresso della Società Italiana di Buiatria, Milan, 1974. Tipografia Editoriale Piacentina Gallarati., Piacenza, Italy.

Cicchetti, D. V., and T. Allison. 1971. A new procedure for assessing reliability of scoring EEG sleep recordings. Am. J. EEG Technol. 11:101-109.

Cohen, J. 1960. A coefficient of agreement for nominal scales. Educ. Psychol. Meas. 20:37-46.

Cohen, J. 1968. Weighted kappa: Nominal scale agreement provision for scaled disagreement or partial credit. Psychol. Bull. 70:213220 .

Dohoo, I., W. Martin, and H. Stryhn. 2003. Veterinary Epidemiologic Research. 1st ed. University of Prince Edward Island, Charlottetown, Prince Edward Island, Canada.

Döpfer, D. 2009. Digital dermatitis. The dynamics of digital dermatitis in dairy cattle and the manageable state of disease. Pages $1-5$ in CanWest Veterinary Conference, Banff, AB, Canada. http://www. hoofhealth.ca/Dopfer.pdf

Döpfer, D., A. Koopmans, F. A. Meijer, I. Szakáll, Y. H. Schukken, W. Klee, R. B. Bosma, J. L. Cornelisse, A. J. van Asten, and A. A. ter Huurne. 1997. Histological and bacteriological evaluation of digital dermatitis in cattle, with special reference to spirochaetes and Campylobacter faecalis. Vet. Rec. 140:620-623.

Fleiss, J. L. 1975. Measuring agreement between two judges on the presence or absence of a trait. Biometrics 31:651-659.

Fourichon, C., H. Seegers, N. Bareille, and F. Beaudeau. 1999. Effects of disease on milk production in the dairy cow: A review. Prev. Vet. Med. 41:1-35.

Greenough, P. R., C. K. W. Muelling, D. Döpfer, and D. J. Tomlinson. 2008. International atlas of lesions of cattle feet. Nomenclature and atlas update. Page 40 in Proc. 15th Intern. Symp. 7th Conf. Lameness Ruminants, Kuopio, Finland.

Hernandez, J., and J. K. Shearer. 2000. Efficacy of oxytetracycline for treatment of papillomatous digital dermatitis lesions on various anatomic locations in dairy cows. J. Am. Vet. Med. Assoc. $216: 1288-1290$

Holzhauer, M., C. J. Bartels, D. Döpfer, and G. van Schaik. 2008a. Clinical course of digital dermatitis lesions in an endemically infected herd without preventive herd strategies. Vet. J. 177:222230

Holzhauer, M., C. J. Bartels, B. H. van den Borne, and G. van Schaik. 2006a. Intra-class correlation attributable to claw trimmers scoring common hind-claw disorders in Dutch dairy herds. Prev. Vet. Med. 75:47-55.
Holzhauer, M., D. Döpfer, J. de Boer, and G. van Schaik. 2008b. Effects of different intervention strategies on the incidence of papillomatous digital dermatitis in dairy cows. Vet. Rec. 162:41-46.

Holzhauer, M., C. Hardenberg, C. J. Bartels, and K. Frankena. 2006b. Herd- and cow-level prevalence of digital dermatitis in the Netherlands and associated risk factors. J. Dairy Sci. 89:580-588.

Hripcsak, G., and D. F. Heitjan. 2002. Measuring agreement in medical informatics reliability studies. J. Biomed. Inform. 35:99-110.

Landis, J. R., and G. G. Koch. 1977. The measurement of observer agreement for categorical data. Biometrics 33:159-174.

Laven, R. A. 1999. The environment and digital dermatitis. Cattle Pract. 7:349-355.

Laven, R. A., and D. N. Logue. 2006. Treatment strategies for digital dermatitis for the UK. Vet. J. 171:79-88.

Manske, T., J. Hultgren, and C. Bergsten. 2002. Prevalence and interrelationships of hoof lesions and lameness in Swedish dairy cows. Prev. Vet. Med. 54:247-263.

Martin, S. W. 1984. Estimating disease prevalence and the interpretation of screening. Prev. Vet. Med. 2:463-472.

Mumba, T., D. Döpfer, C. Kruitwagen, M. Dreher, W. Gaastra, and B. A. van der Zeijst. 1999. Detection of spirochetes by polymerase chain reaction and its relation to the course of digital dermatitis after local antibiotic treatment in dairy cattle. Zentralbl. Veterinarmed. B 46:117-126.

Read, D. H., and R. L. Walker. 1998. Papillomatous digital dermatitis (footwarts) in California dairy cattle: Clinical and gross pathologic findings. J. Vet. Diagn. Invest. 10:67-76.

Rodriguez-Lainz, A., P. Melendez-Retamal, D. W. Hird, and D. H Read. 1998. Papillomatous digital dermatitis in Chilean dairies and evaluation of a screening method. Prev. Vet. Med. 37:197207.

Somers, J. G., W. G. Schouten, K. Frankena, E. N. NoordhuizenStassen, and J. H. Metz. 2005. Development of claw traits and claw lesions in dairy cows kept on different floor systems. J. Dairy Sci. $88: 110-120$.

Thomsen, P. T., I. C. Klaas, and K. Bach. 2008 Short communication: Scoring of digital dermatitis during milking as an alternative to scoring in a hoof trimming chute. J. Dairy Sci. 91:4679-4682.

Walter, S. D., M. Eliasziw, and A. Donner. 1998. Sample size and optimal designs for reliability studies. Stat. Med. 17:101-110

Yano, T., R. Yamagami, K. Misumi, C. Kubota, K. K. Moe, T. Hayashi, K. Yoshitani, O. Ohtake, and N. Misawa. 2009. Genetic heterogeneity among strains of Treponema phagedenis-like spirochetes isolated from dairy cattle with papillomatous digital dermatitis in Japan. J. Clin. Microbiol. 47:727-733. 